\title{
Adsorptive Removal of Azo Dye New Coccine Using High-Performance Adsorbent-Based Polycation-Modified Nano-Alpha Alumina Particles
}

\author{
Thi Hai Yen Doan ${ }^{1},{ }^{1}$ Hong Anh Pham, ${ }^{2}$ Ngoc Huyen Nguyen, ${ }^{2}$ Thi Dung Le, \\ Thanh Binh Nguyen, ${ }^{1}$ and Thanh Son Le ${ }^{1}$ \\ ${ }^{1}$ Faculty of Chemistry, University of Science, Vietnam National University, Hanoi-19 Le Thanh Tong, \\ Hoan Kiem, Hanoi, Vietnam \\ ${ }^{2}$ Nguyen Sieu High School, Yen Hoa, Cau Giay, Hanoi, Vietnam \\ Correspondence should be addressed to Thi Hai Yen Doan; doanthihaiyen110590@gmail.com
}

Received 13 December 2021; Revised 6 January 2022; Accepted 15 January 2022; Published 7 February 2022

Academic Editor: Arun Srivastav

Copyright (c) 2022 Thi Hai Yen Doan et al. This is an open access article distributed under the Creative Commons Attribution License, which permits unrestricted use, distribution, and reproduction in any medium, provided the original work is properly cited.

\begin{abstract}
The azo dyes new coccine (NCC) were successfully removed through the adsorption onto PVBTAC-modified $\alpha$ - $\mathrm{Al}_{2} \mathrm{O}_{3}$ particles. The optimal conditions of both the surface modification by PVBTAC adsorption and the NCC adsorption were thoroughly investigated. Formerly, polycations PVBTAC were adsorbed onto the nanosized $\alpha-\mathrm{Al}_{2} \mathrm{O}_{3}$ particles at $p H 8, \mathrm{NaCl} 100 \mathrm{mM}$, with a contact time of $2 \mathrm{~h}$, and initial concentration of $1000 \mathrm{ppm}$ to modify the $\alpha-\mathrm{Al}_{2} \mathrm{O}_{3}$ surface. Latterly, the NCC adsorptive removal was conducted at $p H 8, \mathrm{NaCl} 10 \mathrm{mM}, \alpha-\mathrm{Al}_{2} \mathrm{O}_{3}$ adsorbent dosage of $3 \mathrm{mg} \mathrm{mL}^{-1}$, and a contact time of $45 \mathrm{~min}$. Interestingly, the optimal $p H$ of 8 potentially applies to treat real wastewater as the environmental $p H$ range is often about 7-8. High removal efficiency and adsorption capacity of the NCC azo dyes were, respectively, found to be approximately $95 \%$ and $3.17 \mathrm{mg} \mathrm{g}^{-1}$ with an initial NCC concentration of $10 \mathrm{ppm}$. The NCC adsorption on the modified $\alpha-\mathrm{Al}_{2} \mathrm{O}_{3}$ particles was well fitted with a Freundlich model isotherm. A pseudo-second kinetic was more suitable for the NCC adsorption on the PVBTAC-modified $\alpha-\mathrm{Al}_{2} \mathrm{O}_{3}$ surface than a pseudo-first kinetic. The NCC adsorptive removal kinetic was also affirmed by the FT-IR spectra, based especially on the changes of functional group stretch vibrations of $-\mathrm{SO}_{3}{ }^{-}$group in the $\mathrm{NCC}$ molecules and $-\mathrm{N}^{+}\left(\mathrm{CH}_{3}\right)_{3}$ group in the PVBTAC molecules. The high reusability of the $\alpha-\mathrm{Al}_{2} \mathrm{O}_{3}$ particles was proved to be higher than $50 \%$ after four generation times.
\end{abstract}

\section{Introduction}

Nowadays, the azo dyes have been diversely used in many industrial applications such as textile, clothing, printing, plastic, and paper productions. The azo dyes that contain a specific group $-\mathrm{N}=\mathrm{N}$ - are the most popular and estimate to be about $50-70 \%$ of annual total dye production [1]. The azo dyes durably exist and are non-degraded in the aquatic environment. Moreover, the effluents from these industries often contain a large dye amount of $10-200 \mathrm{mg} \mathrm{L}^{-1}[2,3]$, which is likely dangerous to the ecosystem and human health, causing biohazard risks such as bioaccumulation and mutagenesis inducing genetical diseases, congenital malformations, or cancer [4-6]. For this reason, the dye elimination from the wastewater is necessary.

The most common dye treatment techniques basing on discoloration are physical, chemical, biological methods, and adsorption [7-12]. For decades, a lot of research on the azo dye demand removal from aqueous solution has been conducted $[10,13]$. Among them, new coccine (NCC), well known with another name as Acid Red 18, has been recently taken the interest of scientists. NCC is one of the synthetic organic azo dyes widely used in textile industries. NCC degradation by using the $\mathrm{TiO}_{2}$ photocatalyst in combination with $\mathrm{H}_{2} \mathrm{O}_{2}$ in a cavitation reactor was intensified up to $88.1 \%$ in comparison to $64.8 \%$ obtained in an ultrasonic reactor. 
NCC degraded up to $99.6 \%$ with the employment of the Fenton reagent combining with UV irradiation (UV/FR) at pH 3 and under $30 \mathrm{~min}$ of reaction time [14]. Among these techniques, adsorption is more effective with high removal efficiency, and simple and low cost. The use of carbon as an adsorbent seems to be popular. NCC was totally removed (higher than $99 \%$ in 10 consecutive cycles) from an aqueous solution through adsorbing on carbon nanotubes coated with chitosan at a high temperature of $323.15 \mathrm{~K}$ [15]. A maximum NCC removal efficiency reached $90.83 \%$ by adsorption onto the almond shell-synthesized activated charcoal at the optimal $p H 2$ [16]. It was found that the use of carbon nanotubes with multiple walls (MWCNTs) could remove $166.67 \mathrm{mg} \mathrm{g}^{-1}$ of the NCC from an aqueous solution at $p H 3$ [17]. On the other hand, other materials are also applied as adsorbents. NCC was removed from wastewater by means of adsorbing onto the powder of zero iron at an acidic condition of $p H 3$ [18]. However, strictly controlled conditions, such as high experimental temperature or/and acidic environment, have been requested as the removal efficiency is still low.

Furthermore, alumina has been well known as a potential adsorbent for organic pollutant treatment. Alpha alumina $\left(\alpha-\mathrm{Al}_{2} \mathrm{O}_{3}\right)$ was characterized with a high specific surface area and existed as the most stable form at high temperature among various alumina forms such as beta $(\beta)$ - and gamma $(\gamma)$ - [19-21]. Recently, the adsorptive removal potential of the organic pollutants was intensified through modifying the $\alpha-\mathrm{Al}_{2} \mathrm{O}_{3}$ surface by polyelectrolyte adsorption, even at room temperature, which was previously proved [22-24]. It was found that the sodium dodecyl sulfate (SDS) surfactant was strongly attached to the alpha alumina of a small specific surface area [23]. Continuously, oxytetracycline antibiotic was adsorptively removed with a high removal efficiency of higher than $90 \%$ by using SDS-modified $\alpha-\mathrm{Al}_{2} \mathrm{O}_{3}$ [24]. The modification of surface materials has been demonstrated to increase the total net surface charges, enhancing adsorptive removal of wastewater pollutants through electrostatic interactions [25-28]. The adsorption mechanism of the azo dyes were followed Langmuir $[15,29]$, Freundlich [15, 30], and two-step models [31], while adsorption kinetics were indicated by first-order and secondorder models [18, 32, 33].

In this study, attention was focused on removing NCC via adsorption onto polycation-modified $\alpha-\mathrm{Al}_{2} \mathrm{O}_{3}$ nanosized particles under different conditions at room temperature. The effectiveness parameters including $\mathrm{pH}$, ionic strength, adsorbent dosage, contact time, and the initial concentration on both $\alpha-\mathrm{Al}_{2} \mathrm{O}_{3}$ modification process and the NCC removal were comprehensively investigated. The adsorption mechanism was discussed based on both the FT-IR spectra and the general adsorption isotherm models such as Langmuir, Freundlich and two-step. Adsorption kinetics were described by the pseudo-first and -second models.

\section{Materials and Methods}

2.1. Materials. Nanosized alpha alumina $\left(\alpha-\mathrm{Al}_{2} \mathrm{O}_{3}\right)$ particles solvothermaly synthesized following the previous method, were used as adsorbents [34]. Accordingly, to precipitate alumina hydroxide, $4 \mathrm{M}$ sodium hydroxide solution was added to $1 \mathrm{M}$ aluminum nitrate solution, respectively prepared from $\mathrm{NaOH}$ pellets and $\left(\mathrm{Al}\left(\mathrm{NO}_{3}\right)_{3}\right.$ (analytical reagent, Merk, Germany). The precipitates were dried at $80^{\circ} \mathrm{C}$ for $24 \mathrm{~h}$ after centrifugation and rising to neutral $p H$ with ultrapure water. Then, the collected precipitates were transformed to $\alpha-\mathrm{Al}_{2} \mathrm{O}_{3}$ at high temperature of $1200^{\circ} \mathrm{C}$ for $12 \mathrm{~h}$. Finally, the $\alpha-\mathrm{Al}_{2} \mathrm{O}_{3}$ were dried and ground after activating by using the solution of $0.05 \mathrm{M}$ $\mathrm{NaOH}$ and rising with ultrapure water several times. A high synthesis yield of the $\alpha-\mathrm{Al}_{2} \mathrm{O}_{3}$ particles was calculated to be approximately $97.23 \pm 1.43 \%$. The $\alpha-\mathrm{Al}_{2} \mathrm{O}_{3}$ particles synthesized were nanosized at about $27 \mathrm{~nm}$ determined by transmission electron microscopy (TEM, H7650, Hitachi, Tokyo, Japan). Homopolymer, poly(vinylbenzyl) trimethylammonium chloride) (PVBTAC) with a molecular weight of $343.45 \mathrm{~g} \mathrm{~mol}^{-1}$ (Hyogo, Japan) was applied as a surface modifier.

The stock PVBTAC solution of $10^{4} \mathrm{ppm}$ was prepared for adsorption experiments. New coccine with a molecular weight of $604.46 \mathrm{~g} \mathrm{~mol}^{-1}$ (NCC, purity $>82 \%$ Merck, Germany) was used as azo dye. The polymer working solutions were diluted from the stock solution. The chemical structures of polycation PVBTAC and the NCC dye were described in Figure 1. The $\mathrm{NaCl}$ solutions of 0.1 and $1 \mathrm{M}$ (prepared from analytical reagent $\mathrm{NaCl}, \mathrm{Merk}$, Germany) were employed to control ionic strength after filtering through cellulose membranes of $0.2 \mu \mathrm{m}$ pore size. Meanwhile, the solutions of $0.1 \mathrm{M} \mathrm{HCl}$ and $0.1 \mathrm{M} \mathrm{NaOH}$ (Merk, Germany) were used to adjust the $p H$ of the solution under a $\mathrm{pH}$ meter (Hanna, USA). All experimental solutions were prepared with ultrapure water (resistance of $18.2 \mathrm{M} \Omega \mathrm{cm}$, Labconco, Kansai, MO, USA).

\subsection{Modification of Alpha-Alumina Using Highly Positively Charged Polycation}

2.2.1. Alpha-alumina Modification by the PVBTAC Adsorption. The nanosized $\alpha-\mathrm{Al}_{2} \mathrm{O}_{3}$ particles were strongly shaken for $2 \mathrm{~h}$ by an orbital shaker before using. To deaggregate particles, the nanosized $\alpha-\mathrm{Al}_{2} \mathrm{O}_{3}$ particles were sonicated for $30 \mathrm{~min}$ before conducting each experimental modification. To modify the particles, suitable PVBTAC stock solution volumes were added to the nanosized $\alpha-\mathrm{Al}_{2} \mathrm{O}_{3}$ particles. The modification experiments were carried out for about $2 \mathrm{~h}$ by vigorously shaking in investigating conditions of $\mathrm{pH}$ and ionic strength. Then, the samples were centrifuged to separate the solid-liquid phases. Finally, the solutions were collected to determine PVBTAC-remaining concentration by ultraviolet-visible (UV-Vis) measurement.

\subsubsection{NCC Adsorptive Removal Using PVBTAC-Modified} Nanosized $\alpha$-Al2O3 Particles. The nanosized $\alpha-\mathrm{Al}_{2} \mathrm{O}_{3}$ particles modified by PVBTAC adsorption at optimal conditions were rinsed with ultrapure water to eliminate excess polycation PVBTAC after centrifuging to release remaining water. Then, these modified materials were used to conduct 
<smiles>CCc1ccc(C[N+](C)(C)C)cc1</smiles>

(a)

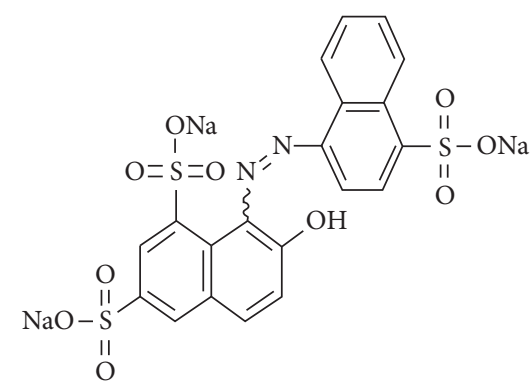

(b)
Figure 1: Chemical structures of (a) PVBTAC and (b) NCC.

dye removal experiments at room temperature and different conditional parameters such as $p H$, ionic strength, adsorption time, $\alpha-\mathrm{Al}_{2} \mathrm{O}_{3}$ adsorbent, and NCC adsorbate dosage. Similarly, the solution was pipetted after centrifugation of the sample. The NCC concentration remaining in the solution was measured by the UV-Vis method. Each experiment was at least triply repeated. Standard deviations were determined by at least triple experiments.

\subsection{Methods}

2.3.1. Ultraviolet Visible (UV-Vis) Spectroscopy. The PVBTAC and NCC concentrations were determined by an UV-Vis spectroscopy equipped with a spectrophotometer (UV-1650 PC, Shimadzu, Japan) at a wavelength of 224 and $508 \mathrm{~nm}$, respectively.

The PVBTAC adsorption efficiency and the NCC removal efficiency $(H, \%)$ were determined

$$
H=\frac{C_{i}-C_{e}}{C_{i}} \times 100 \% .
$$

where $C_{i}$ and $\mathrm{C}_{e}$ are initial and equilibrium polymer concentrations (ppm), respectively.

The polymer adsorption capacities onto unmodified/ modified nanosized $\alpha-\mathrm{Al}_{2} \mathrm{O}_{3}$ particles were determined by equation (2):

$$
\Gamma=\frac{C_{i}-C_{e}}{m} \times M \times 1000,
$$

where $\Gamma$ is the polymer adsorption capacity $\left(\mathrm{mg} \mathrm{g}^{-1}\right)$ at contact time $t$ ( $\mathrm{min}), M$ is polymer molecular weight $\left(\mathrm{g} \mathrm{mol}^{-1}\right)$, and $m$ is the $\alpha-\mathrm{Al}_{2} \mathrm{O}_{3}$ adsorbent dosage $\left(\mathrm{mg} \mathrm{mL}^{-1}\right)$.

2.3.2. Adsorption Mechanism. The adsorption isotherms of PVBTAC onto the $\alpha-\mathrm{Al}_{2} \mathrm{O}_{3}$ particles and NCC onto the PVBTAC-modified $\alpha-\mathrm{Al}_{2} \mathrm{O}_{3}$ particles were considered to be fit with some general adsorption isotherm models such as Langmuir, Freundlich, and two-step [26]. Each adsorption isotherm model was described as below.

First, the Langmuir model described by equation (3) was applicable for absorbate-formed monolayer on the absorbent. The adsorption favorite was evaluated by $R_{L}$ constant as in equation (4).

$$
\begin{aligned}
& \frac{C_{e}}{\Gamma}=\frac{1}{K_{L} \cdot \Gamma_{\max }}+\frac{C_{e}}{\Gamma_{\max }}, \\
& R_{L}=\frac{1}{1+K_{L} \cdot C_{i}} .
\end{aligned}
$$

where $K_{L}$ is Langmuir constant.

Second, the concept of the Freundlich model was developed, based on the experimental data, to evaluate that multiple adsorbate layer formed on the inhomogeneous adsorbent surface. It was subjected in

$$
\Gamma=K_{f} \cdot C_{e}^{n},
$$

where $K_{f}$ is Freundlich constant and $n$ is the layer number.

A general equation of the two-step model adsorption isotherm [34] is as follows:

$$
\Gamma=\frac{\Gamma_{\max } k_{1} C_{e}\left((1 / n)+k_{2} C_{e}^{n-1}\right)}{1+k_{1} C_{e}\left(1+k_{2} C_{e}^{n-1}\right)},
$$

where $k_{1}$ and $k_{2}$ are equilibrium constants for in the first and second adsorption step, respectively.

2.3.3. Adsorption Kinetics. Adsorption kinetics of polymer are often described by the pseudo-first and pseudo-second models proposed by Lagergren as follows $[17,26]$ :

$$
\begin{aligned}
\ln \left(\Gamma_{e}-\Gamma\right) & =\ln \Gamma_{e}-K_{1} t, \\
\frac{t}{\Gamma} & =\frac{1}{K_{2} \cdot \Gamma_{e}^{2}}+\frac{1}{\Gamma_{e}} t,
\end{aligned}
$$

where $\Gamma$ is polymer adsorption capacity at contact time $t$ ( $\mathrm{mg}$ $\left.\mathrm{g}^{-1}\right), \Gamma_{e}$ is the polymer adsorption capacity $\left(\mathrm{mg} \mathrm{g}^{-1}\right)$ at equilibrium state, and $K_{1}\left(\mathrm{~min}^{-1}\right)$ and $K_{2}\left(\mathrm{~g} \mathrm{mg}^{-1} \mathrm{~min}^{-1}\right)$ are reaction rate constants of the pseudo-first and pseudosecond models, respectively.

2.3.4. Fourier Transform Infrared (FT-IR) Spectroscopy. The mechanisms of adsorption of both PVBTAC onto the $\alpha-\mathrm{Al}_{2} \mathrm{O}_{3}$ particles and NCC onto the PVBTAC-modified $\alpha-\mathrm{Al}_{2} \mathrm{O}_{3}$ particles were discussed based on the FT-IR spectra. The PVBTAC adsorption and the NCC adsorption were carried out for $2 \mathrm{~h}$ at $\mathrm{pH} 8$ and at ionic strength of $\mathrm{NaCl} 100$ and $10 \mathrm{mM}$, respectively. Then, the residuals were collected and dried at $80^{\circ} \mathrm{C}$ after centrifugation and removal of the water excess. Five spectra of the $\alpha-\mathrm{Al}_{2} \mathrm{O}_{3}$ particles, PVBTAC, NCC, PVBTAC-modified $\alpha-\mathrm{Al}_{2} \mathrm{O}_{3}$ particles, and NCC-adsorbedPVBTAC-modified $\alpha-\mathrm{Al}_{2} \mathrm{O}_{3}$ particles were recorded from 400 to $4000 \mathrm{~cm}^{-1}$ by an Affinity-1S spectrophotometer $(20$ scans averaging, Shimadzu, Japan) at room temperature (293 K).

\section{Results and Discussions}

\subsection{Modification through PVBTAC Adsorption on the Synthesized Nanosized $\alpha-\mathrm{Al}_{2} \mathrm{O}_{3}$ Particles}

3.1.1. $p H$ Effect. The solution $p H$ significantly affected the PVBTAC adsorption onto the synthesized nanosized 
$\alpha-\mathrm{Al}_{2} \mathrm{O}_{3}$ particles. To modify the $\alpha-\mathrm{Al}_{2} \mathrm{O}_{3}$ particles, an initial PVBTAC concentration of $50 \mathrm{ppm}$ was added to the particles of $5 \mathrm{mg} \mathrm{mL}^{-1}$ in the $p H$ range of 4-12 under different ionic strength conditions of 1,10 , and $100 \mathrm{mM} \mathrm{NaCl}$.

Figure 2 shows that PVBTAC adsorption capacity $\left(\Gamma_{\text {PVBTAC }}\right)$ increased with increasing $p H$ until $p H$ reached 8 , then $\Gamma_{\text {PVBTAC }}$ decreased with continuous increment of the $p H$. The $\alpha-\mathrm{Al}_{2} \mathrm{O}_{3}$ particles were characterized with $-\mathrm{O}$ and $\mathrm{OH}$ functional groups [19] and an isoelectric point (IEP) of approximately 6.7 [35]. It means that the charging sign of the $\alpha-\mathrm{Al}_{2} \mathrm{O}_{3}$ particles changed over the IEP point. At the $p H$ higher than 6.7 , the $\alpha-\mathrm{Al}_{2} \mathrm{O}_{3}$ particle surface was negatively charged due to the presence of $\mathrm{O}^{-}$groups while PVBTAC was positively charged, independently from the $p H$ level. Therefore, the PVBTAC adsorption onto the $\alpha-\mathrm{Al}_{2} \mathrm{O}_{3}$ particles was promoted due to electrostatic attractions at the solution $p H$ greater than 6.7. Oppositely, at a $p H$ lower than 6.7, the $\alpha-\mathrm{Al}_{2} \mathrm{O}_{3}$ particle surface was positively charged due to appearance of the $\mathrm{OH}_{2}^{+}$groups. These surface groups introduced the strong electrostatic repulsions between PVBTAC molecules and the $\alpha-\mathrm{Al}_{2} \mathrm{O}_{3}$ surface, resulting in the limitation of the PVBTAC adsorption. At the solution $\mathrm{pH}$ of 8 , the $\Gamma_{\text {PVBTAC }}$ achieved maximum value at all ionic strengths. Hence, $p H 8$ was chosen to be the optimal modification condition.

3.1.2. Ionic Strength Effect. In addition to the $\mathrm{pH}$ effect, the ionic strength is one of the most effective parameters that influences to the adsorption capacity. The electrolyte shielding effect prevents the hydrophilic interactions and promote the hydrophobic interactions [36-38]. The $\Gamma_{\text {PVBTAC }}$ on the $\alpha-\mathrm{Al}_{2} \mathrm{O}_{3}$ particles was determined at the four $\mathrm{NaCl}$ concentrations of $1,10,100$ and $150 \mathrm{mM}$ at $p H 8$, PVBTAC initial concentration of $50 \mathrm{ppm}$, contact time of $2 \mathrm{~h}$ and a $\alpha-\mathrm{Al}_{2} \mathrm{O}_{3}$ adsorbent dosage of $5 \mathrm{mg} \mathrm{mL}^{-1}$.

As obviously seen in Figure 3 , the $\Gamma_{\text {PVBTAC }}$ increased with increasing the $\mathrm{NaCl}$ concentration from 1 to $100 \mathrm{mM}$ and decreases with continuous salt increment. It was subjected to contributions of different interaction kinds on the PVBTAC adsorption such as electrostatic interactions, including electrostatic attraction and electrostatic repulsion, and nonelectrostatic interactions such as hydrogen bonding and Van der Waals. The Van der Waals not only between PVBTAC and the $\alpha-\mathrm{Al}_{2} \mathrm{O}_{3}$ particles, but also between PVBTAC molecules, might take responsibility for the $\Gamma_{\text {PVBTAC }}$ increment as the $\mathrm{NaCl}$ concentration went up from 1 to $100 \mathrm{mM}$. On the other hand, the electrolyte ions screened the electrostatic attraction between PVBTAC and the absorbent, the $\Gamma_{\text {PVBTAC }}$ quickly dropped while the $\mathrm{NaCl}$ concentration passed $100 \mathrm{mM}$. A maximum $\Gamma_{\text {PVBTAC }}$ of $3.24 \mathrm{mg} \mathrm{g}^{-1}$ was obtained at $\mathrm{NaCl} 100 \mathrm{mM}$. Hence, the ionic strength of $100 \mathrm{mM} \mathrm{NaCl}$ was employed to modify the $\alpha-\mathrm{Al}_{2} \mathrm{O}_{3}$ surface.

3.1.3. PVBTAC Initial Concentration Effect. The polycation initial concentration effect on the $\alpha-\mathrm{Al}_{2} \mathrm{O}_{3}$ modification efficiency was examined with the PVBTAC initial concentration from 25 to $1000 \mathrm{ppm}$ at $\mathrm{pH} \mathrm{8,} \mathrm{NaCl} 100 \mathrm{mM}$, contact time of $2 \mathrm{~h}$. As shown in Figure 4 , the $\Gamma_{\text {PVBTAC }}$ considerably raised from 2.46 to $37 \mathrm{mg} \mathrm{g}^{-1}$ by increasing the PVBTAC

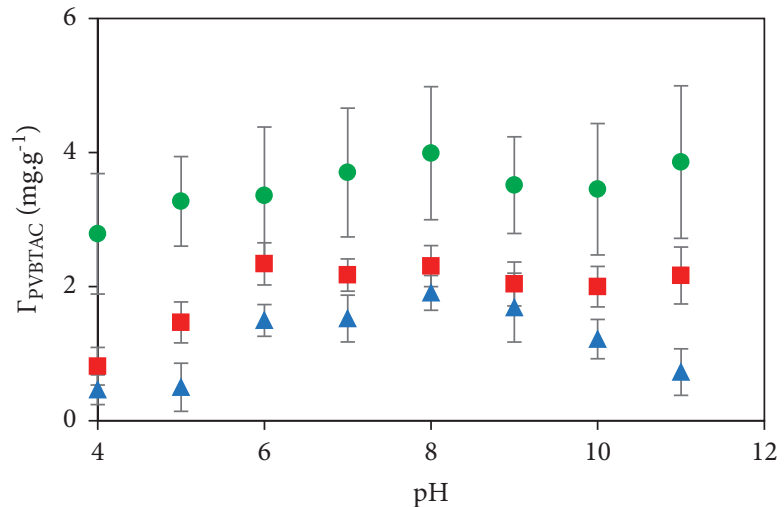

FIgURE 2: $p H$ effect on the PVBTAC adsorption on the $\alpha-\mathrm{Al}_{2} \mathrm{O}_{3}$ particles in different ionic strengths: $(\Delta) 1 \mathrm{mM},(\square) 10 \mathrm{mM}$ and (๑) $100 \mathrm{mM} \mathrm{NaCl}$ with $C_{i, \text { PVBTAC }}$ of $50 \mathrm{ppm}, \mathrm{t}$ of $2 \mathrm{~h}$ and $m_{\alpha \text {-Al2O3 }}$ of $5 \mathrm{mg} \mathrm{mL}^{-1}$.

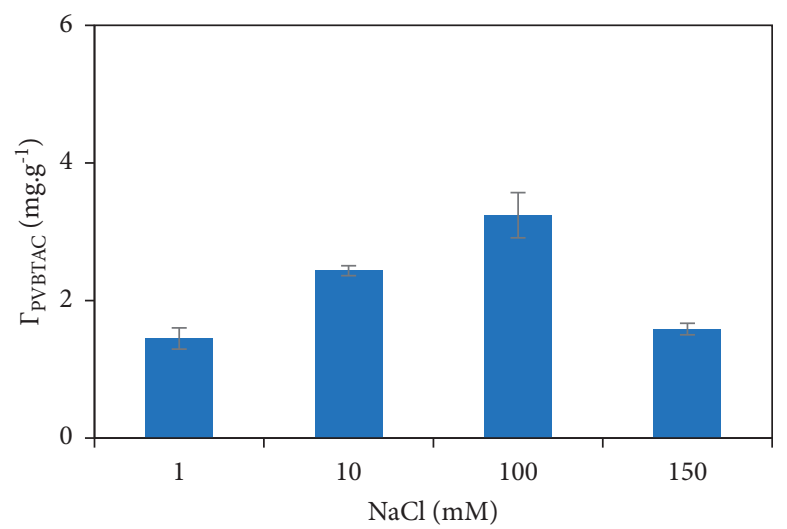

FIgURE 3: Ionic strength effect on the PVBTAC adsorption on the $\alpha-\mathrm{Al}_{2} \mathrm{O}_{3}$ particles at $p H 8, C_{i, \mathrm{PVBTAC}}$ of $50 \mathrm{ppm}, \mathrm{t}$ of $2 \mathrm{~h}$ and $m_{\alpha-}$ $\mathrm{Al} 2 \mathrm{O} 3$ of $5 \mathrm{mg} \mathrm{mL}^{-1}$.

initial concentration in the range of $25-1000 \mathrm{ppm}$. The results can infer that more PVBTAC molecules were diffused and attached to the $\alpha-\mathrm{Al}_{2} \mathrm{O}_{3}$ surface, due to main electrostatic interactions at high PVBTAC initial concentration and vice versa [38]. For the next experiments, the PVBTAC initial concentration of $1000 \mathrm{ppm}$ was used to sufficiently modify the $\alpha-\mathrm{Al}_{2} \mathrm{O}_{3}$ surfaces.

Summarily, the $\alpha-\mathrm{Al}_{2} \mathrm{O}_{3}$ particle modification through PVBTAC adsorption was optimized at $p H 8$, ionic strength of $100 \mathrm{mM}$, contact time of $2 \mathrm{~h}$, and PVBTAC initial concentration of $1000 \mathrm{ppm}$.

3.2. NCC Adsorptive Removal by Using PVBTAC-Modified $\alpha-\mathrm{Al}_{2} \mathrm{O}_{3}$ Particles Confirmed by FT-IR Measurement. The successful $\alpha-\mathrm{Al}_{2} \mathrm{O}_{3}$ surface modification by adsorbing polycation PVBTAC, and the NCC dye adsorptive removal through adsorption onto the PVBTAC-modified particles were confirmed based on the changes of functional groups determined by FT-IR spectroscopy. Formerly, the PVBTAC adsorption onto the $\alpha-\mathrm{Al}_{2} \mathrm{O}_{3}$ particles was affirmed by comparing the FT-IR spectra of the pure $\alpha-\mathrm{Al}_{2} \mathrm{O}_{3}$ particles 


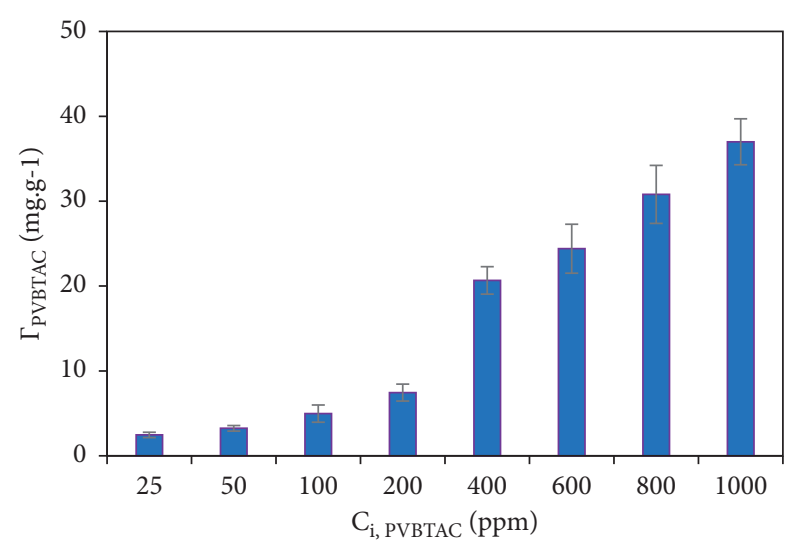

FIGURE 4: Initial concentration effect on the PVBTAC adsorption on the $\alpha-\mathrm{Al}_{2} \mathrm{O}_{3}$ particles at $\mathrm{pH} 8, \mathrm{NaCl} 100 \mathrm{mM}, \mathrm{t}$ of $2 \mathrm{~h}$ and $m_{\alpha-\mathrm{Al} 2 \mathrm{O} 3}$ of $5 \mathrm{mg} \mathrm{mL}^{-1}$.

and the pure PVBTAC with the PVBTAC-modified $\alpha-\mathrm{Al}_{2} \mathrm{O}_{3}$ particle spectrum (Figure 5). The Al-O vibration of the $\alpha-\mathrm{Al}_{2} \mathrm{O}_{3}$ was attributed at $446,552,582,702$, and $756 \mathrm{~cm}^{-1}$ [39] while a sharp peak of $\mathrm{Al}-\mathrm{OH}$ vibration was obtained at $1051 \mathrm{~cm}^{-1}$ [40]. At the investigated $\mathrm{pH} 8$ and $\mathrm{NaCl} 100 \mathrm{mM}$, $\mathrm{O}^{-}, \mathrm{O}$, and $\mathrm{OH}$ groups existed on the $\alpha-\mathrm{Al}_{2} \mathrm{O}_{3}$ surface while only $-\mathrm{N}^{+} R_{3}$ specified for PVBTAC ( $\mathrm{R}$ abbreviating for $\left.-\mathrm{CH}_{3}\right)$. Hence, the functional group vibrations will change if the interactions happen. The sharp peak at $1051 \mathrm{~cm}^{-1}$ presenting for the $\mathrm{Al}-\mathrm{OH}$ vibration of the $\alpha-\mathrm{Al}_{2} \mathrm{O}_{3}$ moved to $1059 \mathrm{~cm}^{-1}$ in the PVBTAC-modified $\alpha-\mathrm{Al}_{2} \mathrm{O}_{3}$ spectrum. Besides, $\mathrm{R}_{3} \mathrm{~N}^{+}-\mathrm{C}$ vibration arose at $1853,2924,3050$, and $3360 \mathrm{~cm}^{-1}$ and especially, a strong band at $976 \mathrm{~cm}^{-1}$ assigned to $\mathrm{C}-\mathrm{N}^{+} R_{3}$ in the PVBTAC spectrum, disappeared in the PVBTAC-modified $\alpha-\mathrm{Al}_{2} \mathrm{O}_{3}$ particle spectrum [41, 42]. These changes recognize the electrostatic attractions between amide in the PVBATC molecule and $\mathrm{O}^{-}$the $\alpha-\mathrm{Al}_{2} \mathrm{O}_{3}$.

Lately, the $S=O$ vibration at 1173 and $1144 \mathrm{~cm}^{-1}$ and the symmetrical $-\mathrm{SO}_{3}{ }^{-}$stretching vibration at $1040 \mathrm{~cm}^{-1}$ of the NCC molecule disappeared in the PVBTAC-modified $\alpha-\mathrm{Al}_{2} \mathrm{O}_{3}$ spectrum [43-45]. In addition to that, the $\mathrm{R}_{3} \mathrm{~N}^{+}-\mathrm{C}$ vibration at $1800-3400 \mathrm{~cm}^{-1}$ and $\mathrm{C}-\mathrm{N}$ peak at $976 \mathrm{~cm}^{-1}$ of PVBTAC in the spectrum of NCC-adsorbed-PVBTACmodified $\alpha-\mathrm{Al}_{2} \mathrm{O}_{3}[41,42]$ were absent, strongly confirming the electrostatic attractions between $-\mathrm{SO}_{3}{ }^{-}$of NCC and $-\mathrm{N}^{+} R_{3}$ of PVBTAC. At the optimal $p H 8$ and $\mathrm{NaCl} 10 \mathrm{mM}$, the $-\mathrm{OH}$ group in the NCC was partly transferred to $\mathrm{OH}_{2}^{+}$as the $\mathrm{pK}_{\mathrm{a}}$ is 11.38 [46], reducing its total negative charges as well as the electrostatic repulsion between the NCC molecules. We might imply that hydrogen bonding was formed among-OH groups between the NCC molecules because the peak at $3399 \mathrm{~cm}^{-1}$ corresponding to $-\mathrm{OH}$ vibration in the NCC molecule, disappeared in the spectrum of NCCadsorbed-PVBTAC-modified $\alpha-\mathrm{Al}_{2} \mathrm{O}_{3}[16,44]$.

\subsection{NCC Removal by Using the PVBTAC-modified $\alpha-\mathrm{Al}_{2} \mathrm{O}_{3}$ Particles}

3.3.1. Ionic Strength Effect. The removal efficiency of $10 \mathrm{ppm}$ initial NCC concentration was more significantly enhanced by using the PVBTAC-modified $\alpha-\mathrm{Al}_{2} \mathrm{O}_{3}$ adsorbents compared with using the unmodified nanosized $\alpha-\mathrm{Al}_{2} \mathrm{O}_{3}$ particles at the same ionic strength of $10 \mathrm{mM} \mathrm{NaCl}$ and all $p H$ (Figure 6). The modification of the $\alpha-\mathrm{Al}_{2} \mathrm{O}_{3}$ adsorbents by PVBTAC adsorption improved the surface net charge, inducing additional electrostatic attractions between the positively charged PVBTAC covered on the $\alpha-\mathrm{Al}_{2} \mathrm{O}_{3}$ surfaces and the negatively charged NCC molecules. Following this, the common effect factors to optimize the NCC removal through adsorbing onto the PVBTAC-modified $\alpha-\mathrm{Al}_{2} \mathrm{O}_{3}$ adsorbents were comprehensively investigated.

As represented in Figure 6, two trends of the ionic strength effect on the NCC removal efficiency were observed. First, the ionic strength increment from 0 to $10 \mathrm{mM}$ $\mathrm{NaCl}$ impulsed the NCC removal efficiency through adsorption onto the PVBTAC-modified $\alpha-\mathrm{Al}_{2} \mathrm{O}_{3}$ particles at all $p H$. It can be explained that the promotion of the hydrogen bonding, and limitation of electrostatic repulsion between the NCC molecules, due to the condenser presence of electrolyte ions mainly controlled the NCC adsorption. However, the NCC removal efficiency decreased as the salt concentration was higher than $100 \mathrm{mM} \mathrm{NaCl}$. The phenomenon suggested the significant shielding electrolyte ion effect on screening the electrostatic attractions between $-\mathrm{N}^{+} R_{3}$ of the PVBTAC and $-\mathrm{SO}_{3}{ }^{-}$of the dye NCC. It was consistent with our previous findings [36-38]. Herein, the NCC removal efficiency strongly depended on the interaction types between the NCC molecules and the PVBTACmodified $\alpha-\mathrm{Al}_{2} \mathrm{O}_{3}$ surface. Therefore, in all experiments, the ionic strength was controlled at $\mathrm{NaCl} 10 \mathrm{mM}$ because the removal efficiency of the NCC was up to approximately $96 \%$ at almost all $\mathrm{pH}$, and the standard deviation was lowest.

3.3.2. pH Effect. As could be seen in Figure 7, the NC removal efficiency, $H_{\mathrm{NCC}}$ and the adsorption amount, $\Gamma_{\mathrm{NCC}}$ unremarkably changed with the wide change of $p H$ from 3 to 12 . PVBTAC is highly positively charged and independent on $p H$. Normally, the $-\mathrm{OH}$ group of the NCC molecule more becomes $-\mathrm{OH}_{2}^{+}$in lower $p H$, reducing the NCC net negative charge. As a result, the electrostatic attraction between PVBCTAC and NCC is less strong at low $p H$ than at high $p H$. However, as observed, the $\mathrm{OH}_{2}^{+}$formation contribution was negligible at $\mathrm{pH}$ lower than $\mathrm{pK}_{\mathrm{a}}$ of NCC $\left(\mathrm{pK}_{\mathrm{a}} 11.38\right)$ [46]. It is suggested that the NCC net charge was mainly decided by the sulfate groups. On the other hand, at the same salt concentration, the $\Gamma_{\mathrm{NCC}}$ got maximum at $p H 8$. The NCC removal was carried out at $p H 8$ and $10 \mathrm{mM} \mathrm{NaCl}$.

3.3.3. Absorbent Dosage Effect. Normally, the total specific area significantly rises with an increment of absorbent dosage, enhancing more effectively adsorptive removal. The removal efficiency gradually changed from $53.94 \%$ to $99.25 \%$ with a 12 -fold increment of the $\alpha-\mathrm{Al}_{2} \mathrm{O}_{3}$ adsorbent dosage from 0.25 to $3 \mathrm{mg} \mathrm{mL}^{-1}$ (Figure 8). Then it was noticeably unchanged at the adsorbent dosage over $3 \mathrm{mg} \mathrm{mL}^{-1}$. Herein, the adsorbent amount of $3 \mathrm{mg} \mathrm{mL}^{-1}$ was sufficient for the adsorptive removal of NCC. 


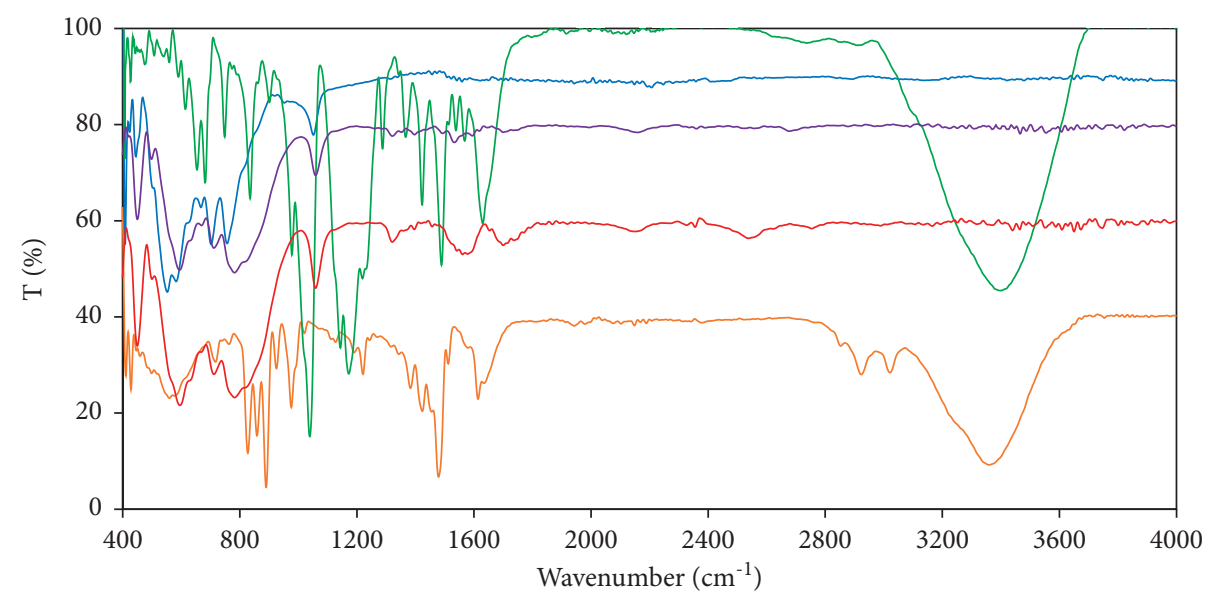

Figure 5: FT-IR spectra of: (-) $\alpha$-Al2O3 particles, (-) polycation PVBTAC, $(-)$ azo dye NCC, (-) PVBTAC-modified $\alpha$-Al2O3 particles and $(-)$ NCC-adsorbed-PVBTAC-modified $\alpha$-Al2O3 particles.

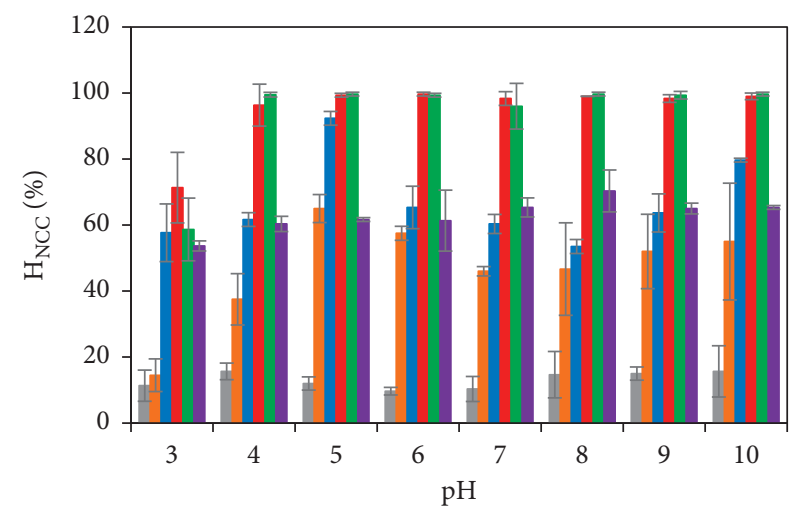

FIgURE 6: Ionic strength effect on the NCC adsorption onto the $\alpha-\mathrm{Al}_{2} \mathrm{O}_{3}$ particles: without PVBTAC modification at $(\square) 10 \mathrm{mM}$

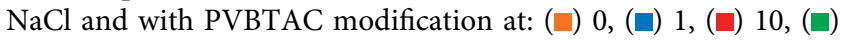
100 and (匹) $200 \mathrm{mM} \mathrm{NaCl}$. Other conditions are $C_{\mathrm{i}, \mathrm{NCC}}$ of $10 \mathrm{ppm}$, $t$ of $2 \mathrm{~h}$, and $m_{\alpha-\mathrm{Al} 2 \mathrm{O} 3}$ of $5 \mathrm{mg} \mathrm{mL}^{-1}$.

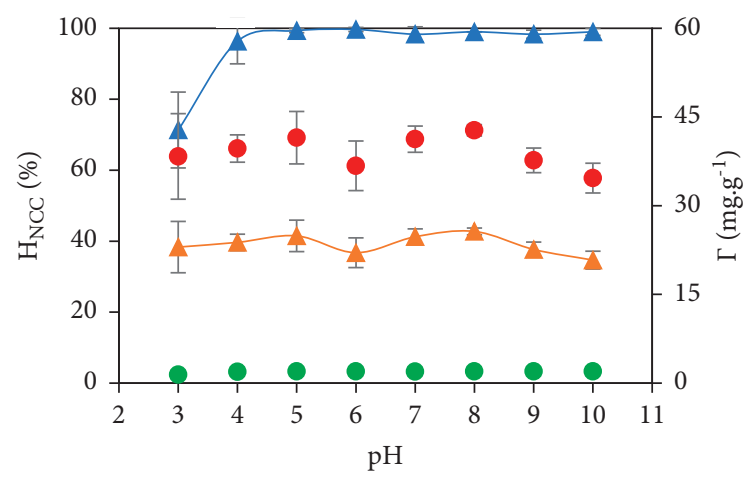

Figure 7: $p H$ effect on the NCC adsorption onto the PVBTACmodified $\alpha-\mathrm{Al}_{2} \mathrm{O}_{3}$ particles at $p H 8, \mathrm{NaCl} 10 \mathrm{mM}, t$ of $2 \mathrm{~h}$ and different conditions as $C_{i, \mathrm{NCC}}$ of $10 \mathrm{ppm}, m_{\alpha-\mathrm{Al} 2 \mathrm{O} 3}$ of $3 \mathrm{mg} \mathrm{mL}^{-1}$ : (A) $H_{\mathrm{NCC}}$ (blue grid line) and (๑) $\Gamma_{\mathrm{NCC}}$ (points); and $C_{i, \mathrm{NCC}}$ of $100 \mathrm{ppm}, m_{\alpha-\mathrm{Al} 2 \mathrm{O} 3}$ of $1 \mathrm{mg} \mathrm{mL}^{-1}$ : (А) $H_{\mathrm{NCC}}$ (orange grid line) and (॰) $\Gamma_{\mathrm{NCC}}$ (points).

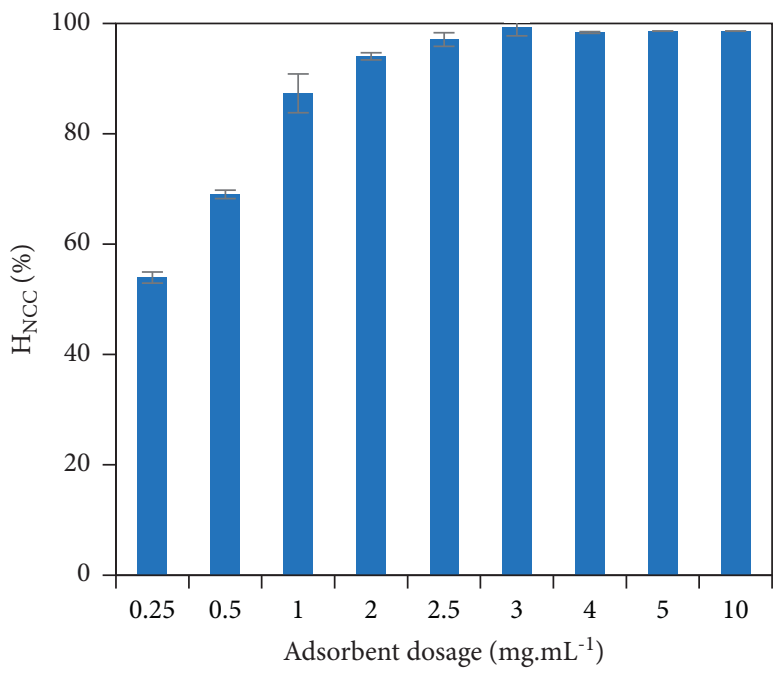

Figure 8: Effects of absorbent dosage on the NCC adsorption onto the PVBTAC-modified $\alpha-\mathrm{Al}_{2} \mathrm{O}_{3}$ particles with $C_{i, \mathrm{NCC}}$ of $10 \mathrm{ppm}$, $p H 8, \mathrm{NaCl} 10 \mathrm{mM}, t$ of $2 \mathrm{~h}$, and $m_{\alpha-\mathrm{Al} 2 \mathrm{O} 3}$ of $3 \mathrm{mg} \mathrm{mL}^{-1}$.

3.3.4. Contact Time Effect. The contact time effect on the NCC removal efficiency can be clearly observed in Figure 9. The NCC removal efficiency raised rapidly in each 15 min of the first $30 \mathrm{~min}$. In the contact time range of $30-45 \mathrm{~min}$, the removal efficiency continuously slowly raised from 96.25 to $97.40 \%$. Then the removal efficiency was kept constant at the high removal efficiency of about $96 \%$ from $45 \mathrm{~min}$ to $120 \mathrm{~min}$ of the contact time. Accordingly, the NCC adsorption on the PVBTAC-modified $\alpha-\mathrm{Al}_{2} \mathrm{O}_{3}$ surface reached an equilibrium state at the contact time of $45 \mathrm{~min}$. Therefore, the optimal contact time of $45 \mathrm{~min}$ was applied for the next investigation.

3.3.5. NCC Adsorption Isotherm Model. The fitness of the NCC adsorption on the PVBTAC-modified $\alpha-\mathrm{Al}_{2} \mathrm{O}_{3}$ particles with Langmuir, Freundlich and two-step models was examined. It can be seen clearly in Figure 10 that $\Gamma_{\text {NCC }}$ 


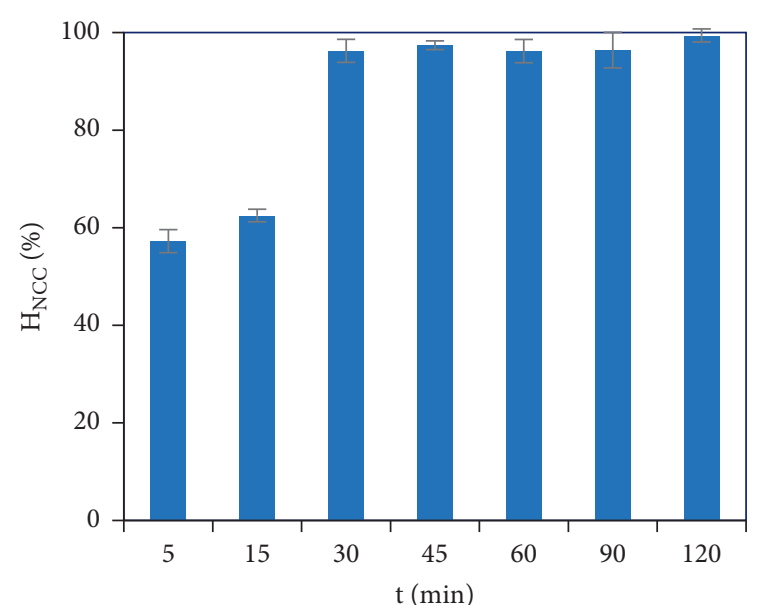

FIGURE 9: Effects of the absorbate dosage on the NCC adsorption onto the PVBTAC-modified $\alpha-\mathrm{Al}_{2} \mathrm{O}_{3}$ particles with $C_{i, \mathrm{NCC}}$ of $10 \mathrm{ppm}, \mathrm{pH} 8, \mathrm{NaCl} 10 \mathrm{mM}$ and $m_{\alpha-\mathrm{Al} 2 \mathrm{O} 3}$ of $3 \mathrm{mg} \mathrm{mL}^{-1}$.

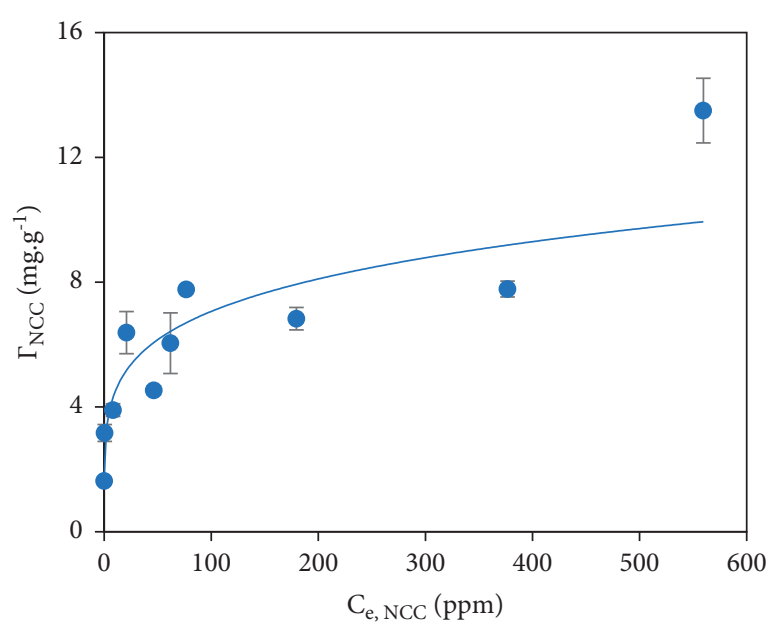

Figure 10: NCC adsorption on the PVBTAC-modified $\alpha-\mathrm{Al}_{2} \mathrm{O}_{3}$ particles was well fitted with Freundlich model at conditions: $C_{i, \mathrm{NCC}}$ from 10 to $600 \mathrm{ppm}, p H 8, \mathrm{NaCl} 10 \mathrm{mM}$, $t$ of $45 \mathrm{~min}$, and $m_{\alpha-}-\mathrm{Al}_{2} \mathrm{O}_{3}$ of $3 \mathrm{mg} \mathrm{mL}^{-1}$.

gradually raised from about 1.62 to $13.5 \mathrm{mg} \mathrm{g}^{-1}$ as the NCC initial concentration increased from 5 to $600 \mathrm{ppm}$. A maximum NCC adsorption capacity of $13.5 \mathrm{mg} \mathrm{g}^{-1} \mathrm{de}-$ termined proves that PVBTAC-modified $\alpha-\mathrm{Al}_{2} \mathrm{O}_{3}$ was high-performance adsorbents in the NCC removal compared with other materials. The NCC adsorption capacity by using PVBTAC-modified $\alpha-\mathrm{Al}_{2} \mathrm{O}_{3}$ particles was higher than using activated carbon as adsorbents (Table 1) [47-49]. Moreover, it might suggest that more numerous surface sites were available for NCC adsorption at low NCC initial concentration, intensifying the electrostatic attractions between NCC and adsorbed PVBTAC. Oppositely, the repulsive interactions between the NCC molecules were dominant at high NCC initial concentration. The NCC adsorptive removal only followed the Freundlich model with the fitting parameters calculated as $K_{f}$ of 2.8341 and $n$ of 0.1983 and not adapted with the Langmuir and two-step models (Figure 10).

3.3.6. NCC Adsorption Kinetics on PVBTAC-Modified $\alpha-\mathrm{Al}_{2} \mathrm{O}_{3}$ Particles. Two kinetic models including pseudofirst and pseudo-second were considered for the NCC adsorption on PVBTAC-modified $\alpha-\mathrm{Al}_{2} \mathrm{O}_{3}$ particles, as indicated in Figure 11.

The NCC adsorption kinetics on the PVBTAC-modified $\alpha-\mathrm{Al}_{2} \mathrm{O}_{3}$ surface were better followed with the pseudo-second model with a higher correlation coefficient $\left(R^{2}\right)$ of 0.9964 than the pseudo-first model with a lower $R^{2}$ of 0.7972 (Figure 11). It was proposed that there were some interactions between the adsorbed NCC molecules. In detail, the interactions might be resulted from hydrogen bondings between $-\mathrm{OH}$ groups in the NCC suggested by the FT-IR spectra above. The fitted parameters were shown in Table 2.

3.3.7. Regeneration of $\alpha-\mathrm{Al}_{2} \mathrm{O}_{3}$ Adsorbent. Formerly, acidic solutions of $1,2,5$ and $10 \mathrm{M} \mathrm{HCl}$ were used to regenerate $\alpha-\mathrm{Al}_{2} \mathrm{O}_{3}$ adsorbent after the NCC adsorption. The regeneration procedure of the $\alpha-\mathrm{Al}_{2} \mathrm{O}_{3}$ adsorbent was conducted twice. For each time, the PVBTAC-modified $\alpha-\mathrm{Al}_{2} \mathrm{O}_{3}$ particles adsorbed the NCC were shaken with desired $\mathrm{HCl}$ concentration for $45 \mathrm{~min}$. Then the concentration of the NCC desorbed was determined by the UV-Vis method at the wavelength of $508 \mathrm{~nm}$. As shown in Figure 12, the NCC desorption efficiency in the first $\mathrm{HCl}$ treatment was low. After $\mathrm{HCl}$ treatment twice, the NCC adsorption efficiency reached higher than $90 \%$ at all $\mathrm{HCl}$ concentration. Moreover, the NCC desorption efficiency slightly raised with increasing 2-fold $\mathrm{HCl}$ concentration from 1 to $2 \mathrm{M}$, and reached maximum (approximately 97\%) at the $\mathrm{HCl}$ higher than $5 \mathrm{M}$. It was referred to elute almost the NCC from the adsorbent surface. More presence of $\mathrm{OH}_{2}^{+}$groups on the particle surface under acidic condition led to stronger electrostatic repulsion between the positively charged PVBTAC and the positively charged $\alpha-\mathrm{Al}_{2} \mathrm{O}_{3}$. As a result, the NCC were desorbed. Therefore, the regeneration of the $\alpha-\mathrm{Al}_{2} \mathrm{O}_{3}$ adsorbent was carried out twice by using the $\mathrm{HCl}$ solution of $5 \mathrm{M}$. Each procedure of the $\mathrm{HCl}$ treatment twice was considered to be a regeneration time. The regeneration treatment of the $\alpha-\mathrm{Al}_{2} \mathrm{O}_{3}$ adsorbents with strong acid at high concentration confirmed strong interactions between NCC and PVBTAC-modified surface, and the high synthesized adsorbent stability.

Lately, the regenerated $\alpha-\mathrm{Al}_{2} \mathrm{O}_{3}$ particles were modified by the PVBTAC adsorption. Then the PVBTAC-modifiedregenerated adsorbents were applied to adsorptively remove NCC. It was seen in Figure 13 that the NCC removal efficiency by using PVBTAC-modified-regenerated adsorbents decreased with rising the regeneration time. However, the NCC removal efficiency, achieved about 53\% after four regeneration times, still was high. It was clarified that high reusability of the $\alpha-\mathrm{Al}_{2} \mathrm{O}_{3}$ adsorbents. 
TABLE 1: NCC adsorption capacities and NCC removal efficiencies by using different adsorbents.

\begin{tabular}{lccc}
\hline Adsorbents & $\begin{array}{c}\text { Adsorption } \\
\text { capacity }\left(\mathrm{mg} \mathrm{g}^{-1}\right)\end{array}$ & Removal efficiency (\%) & References \\
\hline PVBTAC-modified $\alpha-\mathrm{Al}_{2} \mathrm{O}_{3}$ & 13.5 & 97.5 & This study \\
Chemically treated mangrove barks & 12.72 & 25.40 & {$[47]$} \\
Activated carbon prepared from poplar woods & 3.91 & 31.28 & {$[48]$} \\
Activated carbon prepared from almond shells & 10.75 & 90.83 & {$[49]$} \\
\hline
\end{tabular}

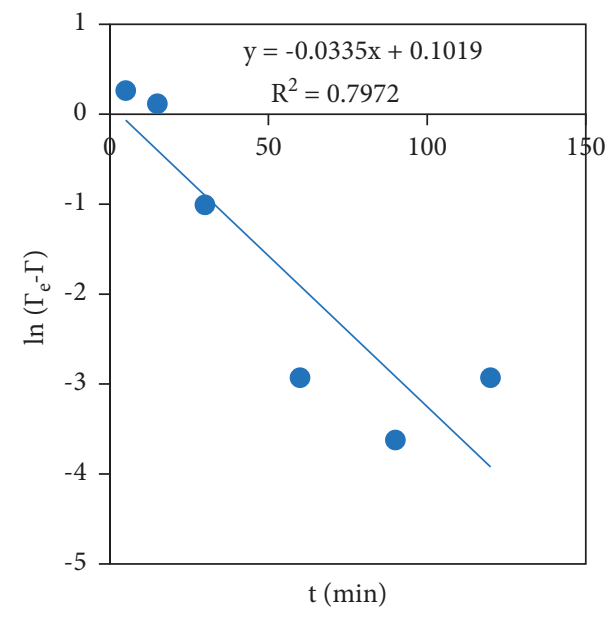

(a)

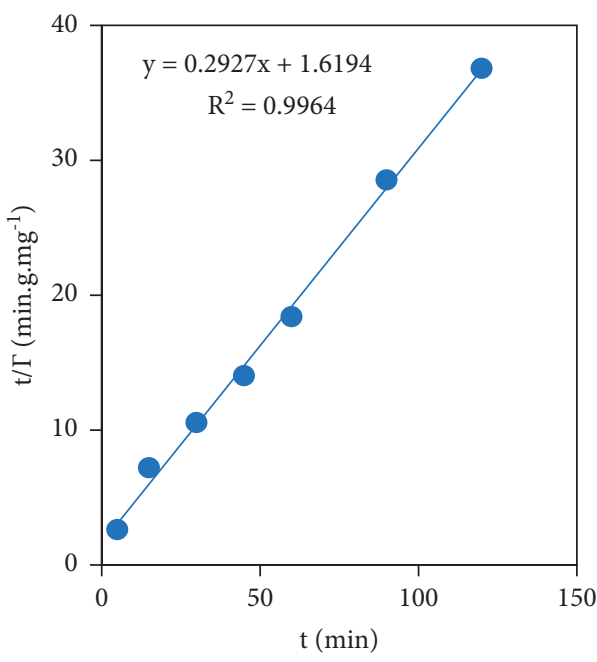

(b)

Figure 11: Kinetics of the PVBTAC adsorption isotherm on the $\alpha-\mathrm{Al}_{2} \mathrm{O}_{3}$ particles following (a) pseudo-first and (b) pseudo-second at conditions of $C_{i}$, NCC of $10 \mathrm{ppm}, \mathrm{pH} 8, \mathrm{NaCl} 10 \mathrm{mM}$, and $m_{\alpha \text {-Al2O3 }}$ of $3 \mathrm{mg} \mathrm{mL}^{-1}$.

TABLE 2: Fitting parameters for the NCC adsorption onto the PVBTAC-modified $\alpha-\mathrm{Al}_{2} \mathrm{O}_{3}$ particles following the pseudo-first and pseudo-second kinetic.

\begin{tabular}{lcccc}
\hline Parameters & $\Gamma_{\mathrm{e}}\left(\mathrm{mg} \cdot \mathrm{g}^{-1}\right)$ & $R^{2}$ & $K_{1}\left(\mathrm{~min}^{-1}\right)$ & $K_{2}\left(\mathrm{~g} \mathrm{mg}^{-1} \mathrm{~min}^{-1}\right)$ \\
\hline Pseudo-first kinetic & 3.21 & 0.7972 & 0.0335 & - \\
Pseudo-second kinetic & 3.21 & 0.9964 & - & 0.0600 \\
\hline
\end{tabular}

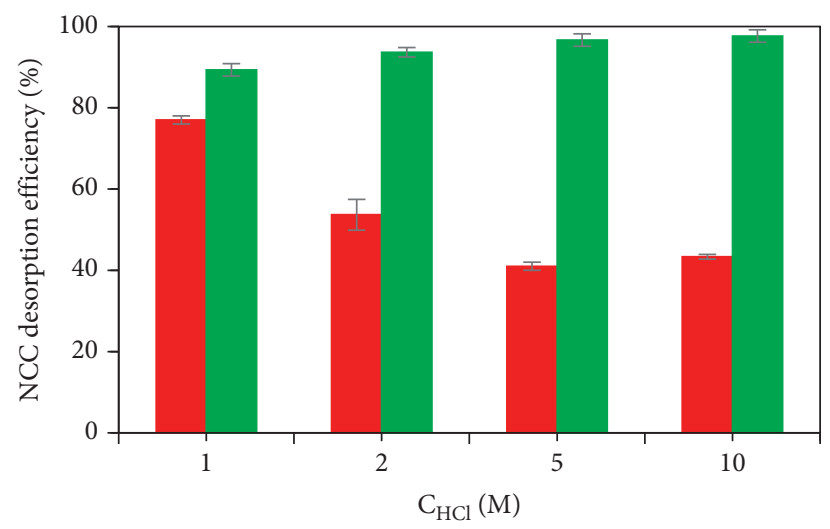

FIGURE 12: Effect of the $\mathrm{HCl}$ concentration to regenerate $\alpha-\mathrm{Al}_{2} \mathrm{O}_{3}$ adsorbent with different $\mathrm{HCl}$ treatment times: $(\square) 1^{\text {st }}$ and ( $\left.\square\right) 2^{\text {nd }}$. 


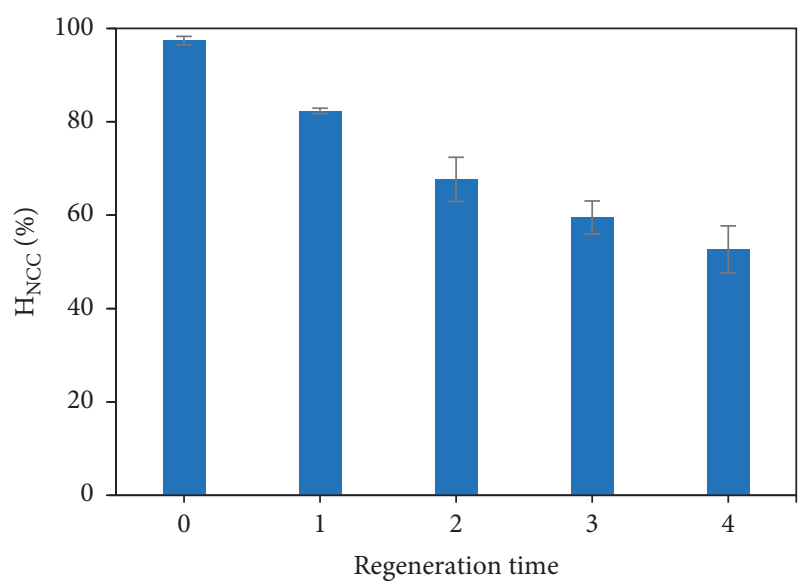

FIgURE 13: The NCC removal efficiency by adsorbing onto the PVBTAC-modified-regenerated $\alpha-\mathrm{Al}_{2} \mathrm{O}_{3}$ adsorbents with different regeneration times at optimal conditions of: $C_{i, \mathrm{NCC}}$ of $10 \mathrm{ppm}, p H$ $8, \mathrm{NaCl} 10 \mathrm{mM}$, and $m_{\alpha-\mathrm{Al} 2 \mathrm{O} 3}$ of $3 \mathrm{mg} \mathrm{mL}^{-1}$.

\section{Conclusions}

In the present study, it was the first time the azo dye NCC was highly adsorptively removed from aqueous solutions by using the PVBTAC polycation-modified $\alpha-\mathrm{Al}_{2} \mathrm{O}_{3}$ particles. Both PVBTAC adsorption and NCC adsorption were comprehensively investigated. To sufficiently modify the $\alpha-\mathrm{Al}_{2} \mathrm{O}_{3}$ particles, polycations PVBTAC of $1000 \mathrm{ppm}$ initial concentration were adsorbed onto $\alpha-\mathrm{Al}_{2} \mathrm{O}_{3}$ for $2 \mathrm{~h}$ at $p \mathrm{H} 8$ under ionic strength of $\mathrm{NaCl} 100 \mathrm{mM}$. Then, the NCC adsorption on the PVBTAC-modified $\alpha-\mathrm{Al}_{2} \mathrm{O}_{3}$ particles was optimized at conditions including $p H 8, \mathrm{NaCl} 10 \mathrm{mM}$, contact time of $45 \mathrm{~min}$, and an $\alpha-\mathrm{Al}_{2} \mathrm{O}_{3}$ dosage of $3 \mathrm{mg} \mathrm{g}^{-1}$. The adsorption of both PVBTAC and NCC was controlled by the electrostatic and non-interaction that also affirmed by the FT-IR spectra. The mechanism and kinetics of the NCC adsorption isotherm onto the PVBTAC-modified $\alpha-\mathrm{Al}_{2} \mathrm{O}_{3}$ particles were clarified. The NCC adsorption isotherm mechanism was in accordance with the Freundlich model, while the NCC adsorption kinetics was more suitably followed by the pseudo-second than the pseudo-first model. The nanosized alpha alumina was proved to be a highly reusable adsorbent.

\section{Data Availability}

All the data and supporting materials are included within the article.

\section{Conflicts of Interest}

All authors declare that there are no conflicts of interest regarding the publication of this paper.

\section{Acknowledgments}

Dr. Thi Hai Yen Doan would like to thank Prof. Shin-ichi Yusa, University of Hyogo, Japan, for supporting polymer materials and Dr. Johan Hunziker, Kobe University, Japan for the available comments and English check to improve our manuscript.

\section{References}

[1] A. G. R Ananthashankar, "Production, characterization and treatment of textile effluents: a critical review," Journal of Chemical Engineering \& Process Technology, vol. 05, no. 01, 2013.

[2] P. Kalyani, "Degradation of toxic dyes-A review," International Journal of Pure \& Applied Bioscience, vol. 4, pp. 81-89, 2016.

[3] D. A. Yaseen and M. Scholz, "Textile dye wastewater characteristics and constituents of synthetic effluents: a critical review," International journal of Environmental Science and Technology, vol. 16, no. 2, pp. 1193-1226, 2019.

[4] B. d. C. Ventura-Camargo and M. A. Marin-Morales, "Azo dyes: characterization and toxicity-A review," Textiles and Light Industrial Science and Technology, vol. 2, 2013, https:// www.researchgate.net/publication/282815745_Azo_Dyes_ Characterization_and_Toxicity-_A_Review.

[5] K.-T. Chung, "Azo dyes and human health: a review," Journal of Environmental Science and Health, Part C, vol. 34, no. 4, pp. 233-261, 2016.

[6] B. Lellis, C. Z. Fávaro-Polonio, J. A. Pamphile, and J. C. Polonio, "Effects of textile dyes on health and the environment and bioremediation potential of living organisms," Biotechnology Research and Innovation, vol. 3, no. 2, pp. 275-290, 2019.

[7] A. Ahmad, S. H. Mohd-Setapar, C. S. Chuong et al., "Recent advances in new generation dye removal technologies: novel search for approaches to reprocess wastewater," RSC Advances, vol. 5, no. 39, pp. 30801-30818, 2015.

[8] S. Papić, N. Koprivanac, A. L. Božić et al., "Advanced oxidation processes in azo dye wastewater treatment," Water Environment Research, vol. 78, no. 6, pp. 572-579, 2006.

[9] S. Ledakowicz and K. Paździor, "Recent achievements in dyes removal focused on advanced oxidation processes integrated with biological methods," Molecules, vol. 26, no. 4, p. 870, 2021.

[10] A. G. Liew Abdullah, M. Salleh, M. K. S. Mazlina et al., “Azo dye removal by adsorption using waste biomass: sugarcane bagasse," International Journal of Engineering and Technology, vol. 2, pp. 8-13, 2005, https://www.researchgate.net/ publication/238086341_Azo_dye_removal_by_adsorption_ using_waste_biomass_Sugarcane_bagasse.

[11] R. G. Saratale, G. D. Saratale, J. S. Chang, and S. P. Govindwar, "Bacterial decolorization and degradation of azo dyes: a review," Journal of the Taiwan Institute of Chemical Engineers, vol. 42, no. 1, pp. 138-157, 2011.

[12] M. Chen, W. Ding, J. Wang, and G. Diao, "Removal of azo dyes from water by combined techniques of adsorption, desorption, and electrolysis based on a supramolecular sorbent," Industrial \& Engineering Chemistry Research, vol. 52, no. 6, pp. 2403-2411, 2013.

[13] G. Ranalli, P. Principi, and C. Sorlini, "Bacterial aerosol emission from wastewater treatment plants: culture methods and bio-molecular tools," Aerobiologia, vol. 16, no. 1, pp. 39-46, 2000.

[14] L. Wang, Y. Han, and L. Li, "Degradation of acid red 18 by Fenton reagent combined with UV," Asian Journal of Chemistry, vol. 22, pp. 6693-6700, 2010.

[15] S. Wang, Y.-Y. Zhai, Q. Gao, W.-J. Luo, H. Xia, and C.-G. Zhou, "Highly efficient removal of acid red 18 from 
aqueous solution by magnetically retrievable chitosan/carbon nanotube: batch study, isotherms, kinetics, and thermodynamics," Journal of Chemical \& Engineering Data, vol. 59, no. 1, pp. 39-51, 2014.

[16] A. A. Najafi Chaleshtori, F. M. Meghadddam, M. M. Sadeghi, R. R. Rahimi, S. Hemati, and A. A. Ahmadi, "Removal of acid red 18 (Azo-dye) from aqueous solution by adsorption onto activated charcoal prepared from almond shell," Journal of Environmental Science and Management, vol. 20, pp. 9-16, 2017, https://www.researchgate.net/publication/323837665_ Removal_of_acid_red_18_Azo-dye_from_aqueous_ solution_by_adsorption_onto_activated_charcoal_prepared_ from_almond_shell.

[17] M. Shirmardi, A. Mesdaghinia, A. H. Mahvi, S. Nasseri, and R. Nabizadeh, "Kinetics and equilibrium studies on adsorption of acid red 18 (Azo-Dye) using multiwall carbon nanotubes (MWCNTs) from aqueous solution," E-Journal of Chemistry, vol. 9, no. 4, pp. 2371-2383, 2012.

[18] M. R. Samarghandi, M. Zarrabi, A. Amrane et al., "Kinetic of degradation of two azo dyes from aqueous solutions by zero iron powder: determination of the optimal conditions," $D e-$ salination and Water Treatment, vol. 40, no. 1-3, pp. 137-143, 2012.

[19] J. W. Ntalikwa, "Determination of surface charge density of $\alpha$-alumina by acid-base titration," Bulletin of the Chemical Society of Ethiopia, vol. 21, no. 1, 2007.

[20] J. P. Maher, "Chapter 4. Aluminium, Gallium, Indium and Thallium," Annual Reports Section "A” (Inorganic Chemistry), vol. 93, pp. 45-58, 1997.

[21] T. Feininger, "Rock-forming minerals. 5A. Non-silicates: oxides, hydroxides, and sulphides (2nd edition)," The Canadian Mineralogist, vol. 495, pp. 1335-1336, 2nd edition, 2011.

[22] T. D. Pham, M. Kobayashi, and Y. Adachi, "Adsorption characteristics of anionic azo dye onto large $\alpha$-alumina beads," Colloid \& Polymer Science, vol. 293, no. 7, pp. 1877-1886, 2015.

[23] T. D. Pham, M. Kobayashi, and Y. Adachi, "Adsorption of anionic surfactant sodium dodecyl sulfate onto alpha alumina with small surface area," Colloid \& Polymer Science, vol. 293, no. 1, pp. 217-227, 2015.

[24] T. D. Pham, T. T. Tran, V. A. Le, T. T. Pham, T. H. Dao, and T. S. Le, "Adsorption characteristics of molecular oxytetracycline onto alumina particles: the role of surface modification with an anionic surfactant," Journal of Molecular Liquids, vol. 287, Article ID 110900, 2019.

[25] S. A. C. Carabineiro, T. Thavorn-Amornsri, M. F. R. Pereira, and J. L. Figueiredo, "Adsorption of ciprofloxacin on surfacemodified carbon materials," Water Research, vol. 45, no. 15, pp. 4583-4591, 2011.

[26] T.-H. Dao, T.-Q.-M. Vu, N.-T. Nguyen et al., "Adsorption characteristics of synthesized polyelectrolytes onto alumina nanoparticles and their application in antibiotic removal," Langmuir, vol. 36, no. 43, pp. 13001-13011, 2020.

[27] T. T. T. Truong, T. N. Vu, T. D. Dinh et al., "Adsorptive removal of cefixime using a novel adsorbent based on synthesized polycation coated nanosilica rice husk," Progress in Organic Coatings, vol. 158, Article ID 106361, 2021.

[28] T. D. Pham, V. P. Bui, T. N. Pham et al., "Adsorptive removal of anionic azo dye new coccine using silica and silica-gel with surface modification by polycation," Polymers, vol. 13, no. 10, p. $1536,2021$.

[29] M. Shabandokht, E. Binaeian, and H.-A. Tayebi, "Adsorption of food dye Acid red 18 onto polyaniline-modified rice husk composite: isotherm and kinetic analysis," Desalination and Water Treatment, vol. 57, pp. 1-13, 2016.

[30] X. Li, A. Li, M. Long, and X. Tian, "Equilibrium and kinetic studies of copper biosorption by dead Ceriporia lacerata biomass isolated from the litter of an invasive plant in China," Journal of Environmental Health Science and Engineering, vol. 13, no. 1, pp. 1-8, 2015.

[31] M. Kuczajowska-Zadrożna, U. Filipkowska, U. Filipkowska, T. Jóźwiak, and P. Szymczyk, "The use of polysaccharides for acid red 18 anionic dye removal from aqueous solutions," Progress on Chemistry and Application of Chitin and its Derivatives, vol. 22, pp. 106-117, 2017.

[32] Z. Liu and K. Xing, "Removal of acid red 88 using activated carbon produced from pomelo peels by $\mathrm{KOH}$ activation: orthogonal experiment, isotherm, and kinetic studies," Journal of Chemistry, vol. 2021, Article ID 6617934, 9 pages, 2021.

[33] L. Zhang and F. Wang, "Kinetics and characteristics studies on biosorption of acid red 18 from aqueous solution by the acid-treated mycelia pellets of Penicillium janthinellum," Desalination and Water Treatment, vol. 167, pp. 313-323, 2019.

[34] N. T. Nguyen, T. H. Dao, T. T. Truong, T. M. T. Nguyen, and T. D. Pham, "Adsorption characteristic of ciprofloxacin antibiotic onto synthesized alpha alumina nanoparticles with surface modification by polyanion," Journal of Molecular Liquids, vol. 309, Article ID 113150, 2020.

[35] T. D. Pham, M. Kobayashi, and Y. Adachi, "Interfacial characterization of $\alpha$-alumina with small surface area by streaming potential and chromatography," Colloids and Surfaces A: Physicochemical and Engineering Aspects, vol. 436, pp. 148-157, 2013.

[36] T. H. Y. Doan, T. D. Pham, J. Hunziker, and T. H. Hoang, "Temporal changes of adsorbed layer thickness and electrophoresis of polystyrene sulfate latex particles after long incubation of oppositely charged polyelectrolytes with different charge densities," Polymers, vol. 13, no. 15, p. 2394, 2021.

[37] T. H. Y. Doan, V. H. Lim, Y. Adachi, and T. D. Pham, "Adsorption of binary mixture of highly positively charged PTMA5M and partially negatively charged PAA onto PSL particles studied by means of brownian motion particle tracking and electrophoresis," Langmuir, vol. 37, no. 41, pp. 12204-12212, 2021.

[38] T. H. Y. Doan and Y. Adachi, "Relaxation of adsorbed layer thickness and electrophoresis of polystyrene latex particles after overshooting of polyelectrolytes with different charge density," Colloids and Surfaces A: Physicochemical and Engineering Aspects, vol. 603, Article ID 125208, 2020.

[39] A. Boumaza, A. Djelloul, and F. Guerrab, "Specific signatures of $\alpha$-alumina powders prepared by calcination of boehmite or gibbsite," Powder Technology, vol. 201, no. 2, pp. 177-180, 2010.

[40] C. Ma, Y. Chang, W. Ye, W. Shang, and C. Wang, "Supercritical preparation of hexagonal $\gamma$-alumina nanosheets and its electrocatalytic properties," Journal of Colloid and Interface Science, vol. 317, no. 1, pp. 148-154, 2008.

[41] Y. Ji, X. Yang, Z. Ji et al., "DFT-calculated IR spectrum amide I, II, and III band contributions of N-methylacetamide fine components," ACS Omega, vol. 5, no. 15, pp. 8572-8578, 2020.

[42] M. S. Agashe and C. I. Jose, "Characteristic vibrations of $-\mathrm{N}(\mathrm{CH} 3) 2$ and $-\mathrm{N}+(\mathrm{CH} 3) 3$ groups in dimethyl aminophenols and their methiodides," Journal of the Chemical Society, Faraday Transactions 2, vol. 73, no. 7, pp. 1232-1237, 1977.

[43] S. B. Brijmohan, S. Swier, R. A. Weiss, and M. T. Shaw, "Synthesis and characterization of cross-linked sulfonated 
polystyrene nanoparticles," Industrial \& Engineering Chemistry Research, vol. 44, no. 21, pp. 8039-8045, 2005.

[44] C. O. M'Bareck, Q. T. Nguyen, M. Metayer, J. M. Saiter, and M. R. Garda, "Poly (acrylic acid) and poly (sodium styrenesulfonate) compatibility by Fourier transform infrared and differential scanning calorimetry," Polymer, vol. 45, no. 12, pp. 4181-4187, 2004

[45] M. Wawrzkiewicz, B. Podkościelna, and P. Podkościelny, "Application of functionalized dvb-co-gma polymeric microspheres in the enhanced sorption process of hazardous dyes from dyeing baths," Molecules, vol. 25, no. 22, p. 5247, 2020.

[46] S. Ötles, Handbook of Food Analysis Instruments, CRC Press, Boca Raton, FL, USA, 2016.

[47] L. S. Tan and M. J. N. Kassim, "Acidic and basic dyes removal by adsorption on chemically treated mangrove barks," International Journal of Applied Science and Technology, vol. 2, pp. 270-276, 2012.

[48] R. Shokoohi, V. Vatanpoor, M. Zarrabi, and A. Vatani, "Adsorption of acid red 18 (AR18) by activated carbon from poplar wood- A kinetic and equilibrium study," E-Journal of Chemistry, vol. 7, no. 1, pp. 65-72, 2010.

[49] A. A. Najafi Chaleshtori, F. M. Meghadddam, M. M. Sadeghi, R. R. Rahimi, S. Hemati, and A. A. Ahmadi, "Removal of acid red 18 (Azo-dye) from aqueous solution by adsorption onto activated charcoal prepared from almond shell," Journal of Environmental Science and Management, vol. 20, pp. 9-16, 2017, https://ovcre.uplb.edu.ph/journals-uplb/index.php/ JESAM/article/view/119. 